\title{
Drones in Academic Apprenticeship. Regarding to Expectations and Consequences for an Up-To-Date Education in Sports Journalism and Media Management
}

\author{
By Andreas Hebbel-Seeger* \\ Thomas Horky ${ }^{\dagger}$
}

\begin{abstract}
Video drones not only offer new perspectives but also an extension of the ways in which stories can be told in sports and event communication can be operated. On the one hand perceptual psychological mechanisms, which are already well-known from the production of films (such as, for example, the power and overview suggestive from the top to bottom view), have an effect. On the other hand, the view from the top of a sports event also provides new information that cannot be generated otherwise and whose use significantly changes the staging of sports, sports reporting and sports training. On selected examples from different sports we show that the exploitation of surplus values in the sense mentioned above does not only depend on the increased camera position. Rather it is crucial to capture and understand the domain-specific peculiarities of a sport in order to profitably exploit the freedom degrees of a drone deployment, taking into account the respective profile of requirements and the intended communication target. It is a question of whether a sporting event should unfold below a drone hovering on a fixed position or the drone should follow an athlete or an overall situation. It depends on the extent and distance of the drone deployment, whether and in which angle a movement path is crossed or an event is encircled, etc. An up-to-date education in media management as well as in sports journalism must not only enable students to tap and understand the profile of requirements in sports and their concretization in the competition but also to take into account the possibilities of communication extended with the use of video drones as well as for spectators, for a live audience and for media-mediated communication. In doing so, aesthetic, journalistic and economic aspects must be taken into account as well as dataand security-legal concerns and psychological effects.
\end{abstract}

Keywords: Drones, Higher Education, Media Management, Project Studies, Sports Communication, Sports Journalism

\section{Introduction}

The demand for academic training is based on contemporary learning opportunities and is oriented towards current developments in research and application practice. In the course of digitization, higher education training is also to become digital; combined with the goal of increasing the quality and efficiency of teaching (Arnold et al. 2015, Handke 2017). Beyond the question of equipping

*Local Head and Professor, Media School, Germany.

†Professor, Macromedia University, Germany. 
and qualifying employees, digitization primarily raises methodological questions in higher education, since digitization cannot "simply" mean transferring previous teaching formats from an analog into a digital environment.

It is certainly no coincidence therefore, that many colleges and universities are again turning to research orientation in teaching; an ideal in the sense of "education through science" (Nieke and von Freytag-Loringhoven 2016). The spectrum of research-oriented formats ranges from genetic learning, in which students use the model to understand how research can be conducted, to forms of teaching research with exercise character, to real student research projects (ibid). The latter although the most desirable, places the highest demands and is most likely to create those moments of tension that university teaching today generally has to cope with: for example, the tension between curious-creative learning and formal assessment or between complex project-oriented learning and scarce support resources (Fung 2017).

Reinmann points out that "the term "research-oriented" ... is just as ambiguous as the related terms problem-, case- or project-oriented." (Reinmann 2016: 225). And further "What unites problem-, project-, caseand research-oriented learning is that all the forms of learning mentioned are problem-oriented in the broader sense (De Graaff and Kolmos 2006). The addition "in the broader sense" is necessary because one must assume a broad problem term." (ibid: 228)

There are many prerequisites to providing demanding research projects as part of a higher education. Research-based learning in the sense of an independently conducted and comprehensive research activity provides only one possible solution. Although it would seem to be a particularly valuable solution in theory, in practice it is not possible to offer to all students equally, at all times, for all subject matters or in a manner appropriate for all student settings. Mieg and Lehmann (2017: 62) therefore split research-related learning into four levels: research-led, research-accompanying, research-oriented and research-based learning. In her model of academic teaching, Reimann (2016) designs three levels of research orientation with different degrees of maturity, which she assigns to three ideal-types of learning spaces (cf. Figure 1).

The aim of the Experimental Space is to initiate the development of explorative attitude. Students should learn to recognize problems, formulate research questions, and ask questions in the search for scientific findings and question "discoveries" critically. The aim is to arouse curiosity, motivate students to engage in research and develop their first problem-solving ideas.

In the Information Space, the focus lies on the acquisition of knowledge about the research activity itself. The students have to answer questions in a scientific manner, cope with failure, recognize hurdles as well as tackle some of them, test out research methods and come up with ideas and solutions of one's own.

Lastly, the Research Space aims to integrate student research activities into a so-called "research stream". The emergent of this research stream can result in new research questions and ideas, data requiring further processing or advanced 
research results and products (artifacts). The output is not only important for students' personal development, but also for third parties.

Figure 1. Model of Academic Teaching

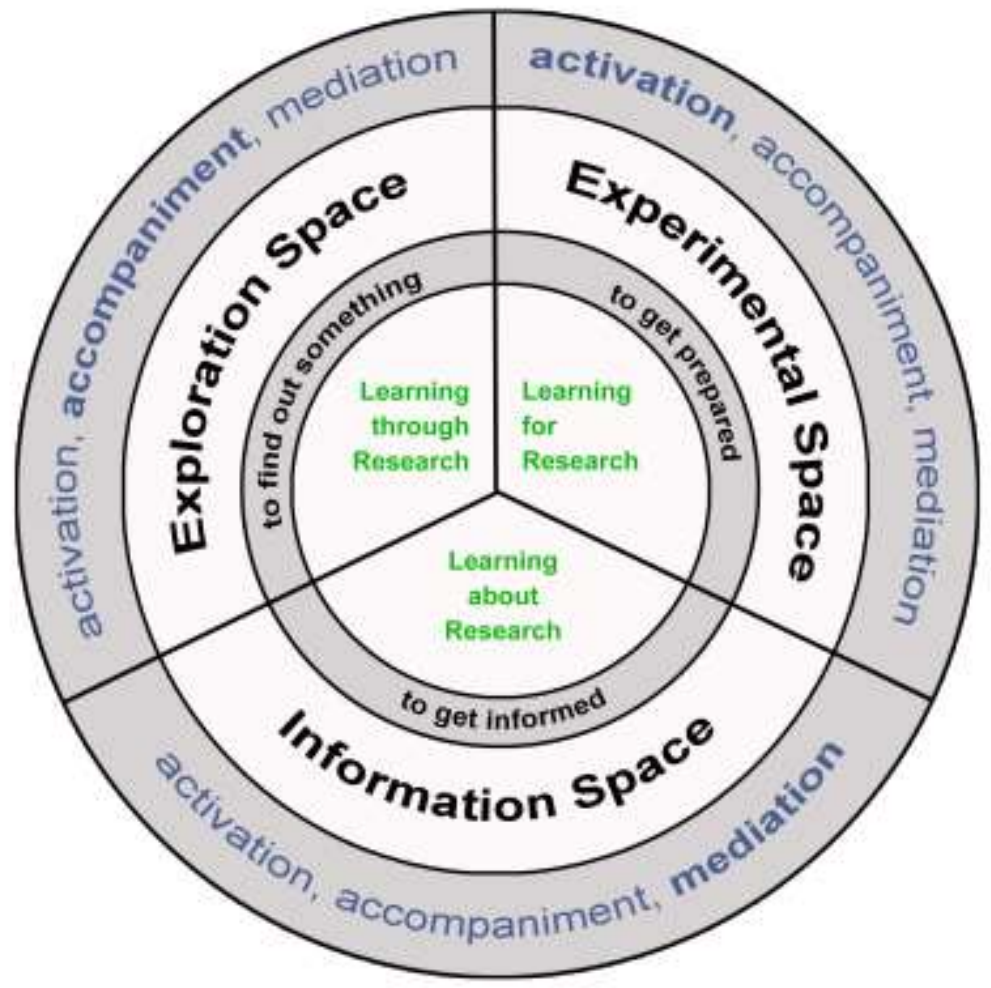

Source: Reinmann 2016, S. 236.

The examination of a learning object is based on three different didactic levels, depending on the respective degree of maturity of the research orientation:

1. Individual level: Activating a student's interest in research, requires tasks that motivate them to analyze the content conveyed, ask their own questions and look at factual circumstances from different perspectives. Depending on the degree of maturity of the research orientation, this can promote personal development or represent the start of their own (partial or complete) research activities.

2. Social level: In the case of larger groups of students, the support of research activities can only be undertaken to a limited extent by teachers. Therefore, various forms of self-evaluation, guided peer review procedures and technical aids (e.g. by evaluating and filtering artifacts) with a feedback function are required (e.g. through the use of collaborative video technology in the sense of a "Social Video Learning"; Vohle 2016).

3. Organizational level: The resulting output from research projects (questions, reflections, data, analyses, experiences, artefacts) must be collected, aggregated, potentially collaboratively evaluated and in the best case used in and for "real" research. This requires innovative forms of 
controlling research flows as well as open access (in particular as defined by Open Educational Resources, OER), standards as well as a high level of discoverability.

In the course of the project studies at the Hamburg campus of the Macromedia University of Applied Sciences, we made video drones the subject of practical research in different kinds of courses of study (journalism and media management), with students from various fields of study. In general, project studies are based on the approaches of discovery and experimental learning (Huber 2009, Kolb 1984, Reinmann 2011, Scheidewind and Singer-Brodowski 2015).

In this context, discovery learning... means the attempt to develop and provide demanding learning environments on the basis professional, subjectspecific and general didactic as well as learning psychology and methodological knowledge" (Schneider 2016: 108).

In the research orientation of this study project, we followed the design-based research approach (Design-Based Research Collective 2003, McKenney and Reeves 2012). In this article we discuss the special suitability and the importance of working with video drones in the sense of research-oriented teaching within the framework of a study project in the courses of study mentioned. While doing so, we rely on selected examples from our own teaching practice.

\section{Video Drones as an Object of Exploratory Learning}

Drones are a technological innovation that affects almost all areas of society. The use of drones as a reporting tool is of particular interest in (sports) journalism and media management; from crisis communication to event communication (Chamberlain 2017, Perrit and Sprague 2017). Drones are themselves the subject of reporting, when their use is staged as a competition (Stock 2015). Drones are an intervention factor if, for example, they are used for ambush marketing in the context of major sporting events, for spying on competing athletes or sports teams, or if they are intended to distort competition by acting as a guiding instrument. Examples of this can be found in sailing, running competitions and cycling (Hebbel-Seeger 2016). Furthermore, drones have long since become an object of marketing, which is to be positively charged by a presentation in sporting environments, among other things, in order to promote a penetration of the mass market.

Drones literally open up a new view of movement and sport, based on perceptual psychological findings. A view from above, for example, generally suggests a feeling of complete perspective and power (Hebbel-Seeger 2016). At the same time, the use of video drones provides access to new information via the new perspective on an event. Connections become visible that could not have been generated before, at least not outside the standard sports facilities. However, the additional merits outlined from the use of video drones, by no means present 
themselves "automatically". Rather, a specific situation analysis is required, which includes the framework (and legal) requirements, as well as the specific characteristics of the sport and the organization of the competition. The choice of technology, in terms of camera systems, flight times and speed (including tracking systems, etc.) are also relevant aspects.

The use of drones is by no means undisputed. Drones objectively pose physical hazards in the event of a crash. In operation, drones generate noises that can affect the athletes' concentration in certain contexts or only superimpose the event experience on the spectator side. Since athletes and spectators on the ground cannot see whether and what an object in the sky is filming, there is also the danger of creating a feeling of insecurity, surveillance and control among outsiders simply by using drones (Hebbel-Seeger et al. 2017).

In summary, video drones currently represent a highly complex field of research that is in particular relevant in the context of sport and sporting events. The field of research covers various topics, such as the stakeholders' acceptance of the technology, the recording of technological and technical requirements, the integration into and modification of existing forms of event communication and domain-specific analyses of sports, competition formats and communication situations under consideration of legal requirements.

Design-based approaches such as "Design-Based Research" (DBR) are particularly suitable for dealing with this research field within the framework of academic teaching. On the one hand, DBR can provide practical educational benefits for digital higher education (e.g. also in the sense of competence orientation; cf. Schaper 2012, 2014) and, on the other hand, theoretical findings can be gained in the research debate, which in turn promote the development of knowledge which can be applied in a generalized way, and thus directly contribute to the study goal and vocational orientation.

An ideal-typical DBR process is based on a concrete practical (learning) problem for which a solution has to be developed. In the context of a journalism or media management course, this can be, for example, a communication issue that should succeed under specific conditions.

Starting with the analysis of a problem or question, possible solutions are designed in a design phase and tested as prototypes. Following the DBR approach, this process is an inherent part of the research process, i.e. neither upstream, as in evaluation, nor downstream, for example as the application and transfer of study results. The particular creative challenge here is the development of a digital educational space that takes into account the different levels of maturity of research orientation as well as the different methods of knowledge (e.g. in projects with students from different fields of study and semesters and with different stakeholders). Starting with a question outlined above, which is derived from the analysis of a problem, the students design concepts for the use of drone technology, develop prototypes and test these in the respective field. The testing is accompanied analytically, and the knowledge gained flows on the one hand into a further development of the respective pilot and on the other hand manifests itself through abstraction and generalization as contributors to the research stream. All in all, DBR is therefore an empirical approach: problems and challenges are 
examined using empirical methods as a starting point; intermediate results are formatively evaluated, if necessary also experimentally investigated and mature solutions are summative analyzed. Empiricism is thus both a reference to reality and to realization for emerging interventions.

Theoretical references arise time and again when working through the first phase of the research, and later on when one's own findings are classified and evaluated against the background of the existing findings. Correspondingly, on the one hand a theory application and on the other hand a theory review up to a modification and theory formation takes place. In the debate about the use of video drones from the perspective of sports journalists and media managers, video drones are combined with communication theory findings, aspects of the perception theory are considered, findings from training science are taken into account and overall (media) economic and sociological theories are looked at.

In a cooperation project with the German Motorsport Federation (Deutscher Motorsport Bund - DMSB) and Ghostthinker GmbH (Hebbel-Seeger and Vohle 2016), for example, we have agreed to optimize the training of marshals in motorsport. The learning and application situation is characterized by comparatively short training periods and high staff turnover. At the same time, marshals in motorsport operate in a highly complex environment, in which the marshals themselves are exposed to a high risk and at the same time have to make decisions under time pressure to certain situations, in coordination with others, in order to avert or at least minimize the physical danger to the athletes in accidents and dangerous situations. The problem to be worked on (and solved) by the students in the context of a study project was thus to professionalize the training of marshals using innovative media technologies. In a first step, the students took on the analysis of the problem: what is the requirement profile for marshals, what are the ideal-typical patterns of action, etc. On the other hand, they dealt with the technological possibilities and the technology of video drones as a tool for the creation of learning materials. In the design phase, concepts for the creation of learning films were developed as different perspectives, implemented in practice, the results reflected and also evaluated with the target group. The results were incorporated into the modification of the concepts for the learning films, which in turn led to new media productions in iterative loops. This work was theory-based, as it were, in that the students acquired domain-specific knowledge in relation to the learning object (motor sports) and the production tools (video drones) and had to deal with familiar media usage behavior as well as learning theory basics, models of perception psychology and the use of video for learning purposes. 
Figure 2. Media Production with the Aim of Professionalizing the Training of Marshals in Motor Sports

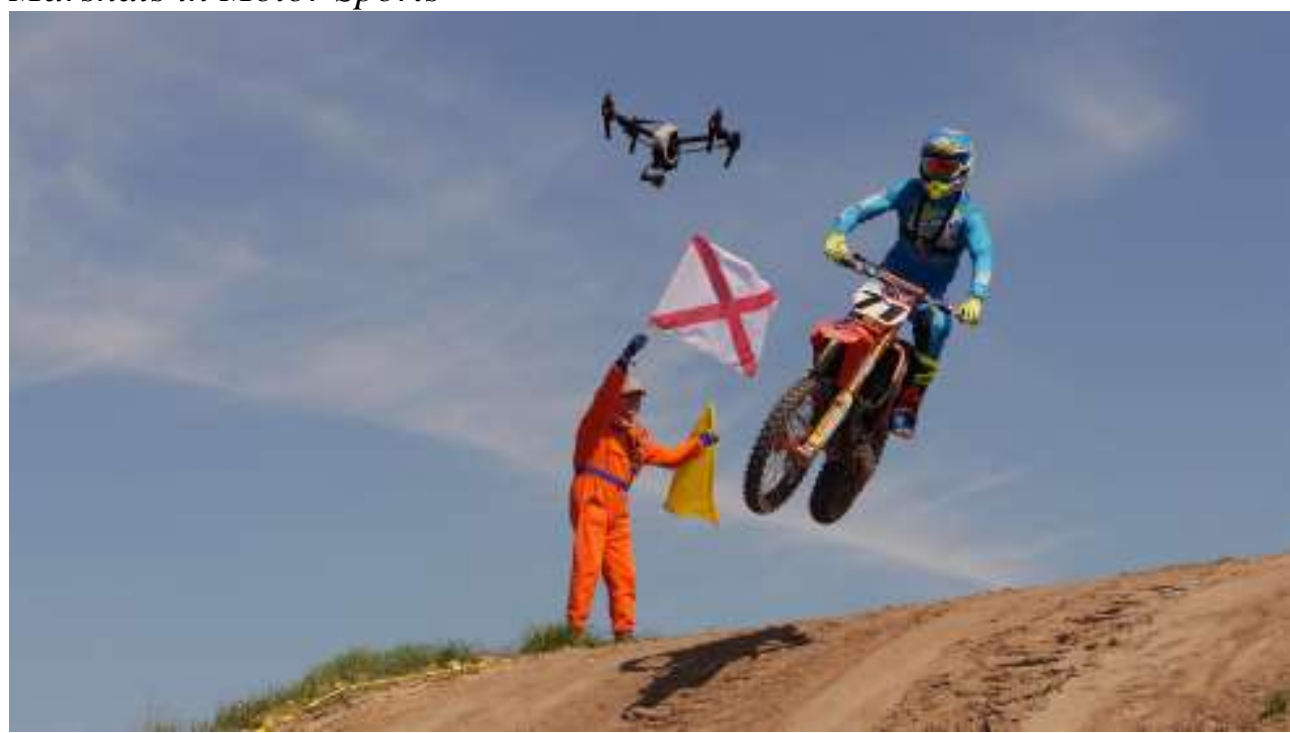

Source: Hebbel-Seeger.

Another study project in cooperation with the German Sailing Association (Deutscher Segler Verband - DSV) focused on the optimization of training processes in sailing using innovative media technologies. The starting point was the analysis of the requirements profile in different boat classes as well as the personnel and material basic conditions in competitive sailing training with the aim of identifying possible optimization potentials (problem definition). Through the theoretical-practical examination of various new media technologies, including video drones, the students conceived and tested the use of these technologies in sailing training (design). The guiding principle here was to find out by means of which visualization the training content could most effectively be presented with the best reflection, for athletes and trainers alike. Time and again, various questions arose. Which aspects of the action situation required a classification into larger spatial contexts (e.g. situational aspects, such as wind or waves, spaceconstituting objects, such as coastlines or navigation marks, or the position and movement of competing teams)? What could possibly be illustrated with a focus on individual athletes, the interaction of athletes within a team or the observation of the overall system of athletes and boat from what perspective, at what distance and with what spatial paths of camera and object to be depicted? Analogous to the procedure outlined above in motor sports, the (interim) results were reflected with the target groups and incorporated into modifications of the visualization concepts. 
Figure 3. Analysis and Reflection of Videographed Training Units Using the Method of Noisy Thinking (Van Someren et al. 1994)

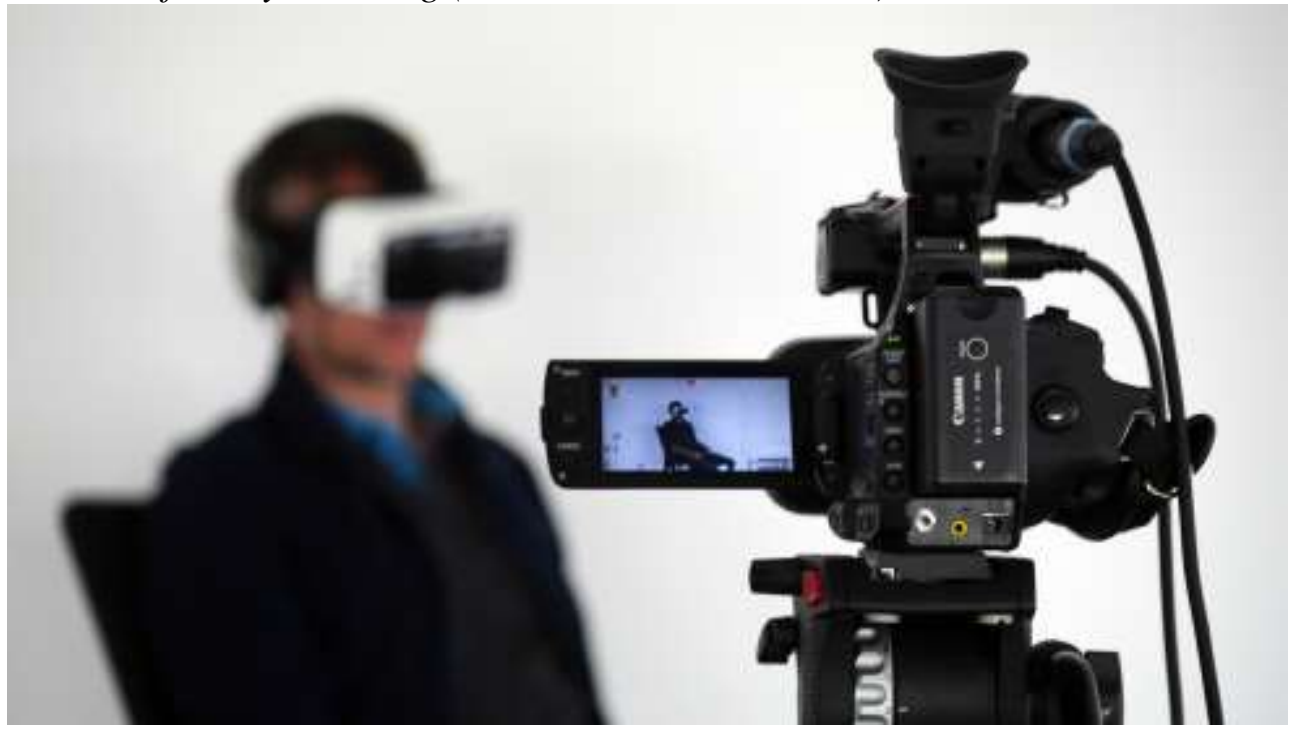

Source: Hebbel-Seeger.

This step was accompanied by the application of theories from different scientific disciplines (in particular sports science/training science and (perception) psychology) and resulted in a critical evaluation of theories, which in turn flowed into theory building when experiences of the use of video drones were generalized under different objectives: Alleged conflicts between the film recordings, which are oriented towards the principles of aesthetic image design, and the informative approaches on the part of activists and trainers, hoped for from a visualization of a course of action, called for specific solutions which were translated into idealtypical solution patterns taking into account existing general theories about the abstraction of situation parameters and training content.

Figure 4. A View From Above: The Microcosm on Board a Sailing Dinghy, the Room Layout in a Competition Situation and the Complex Space for Action

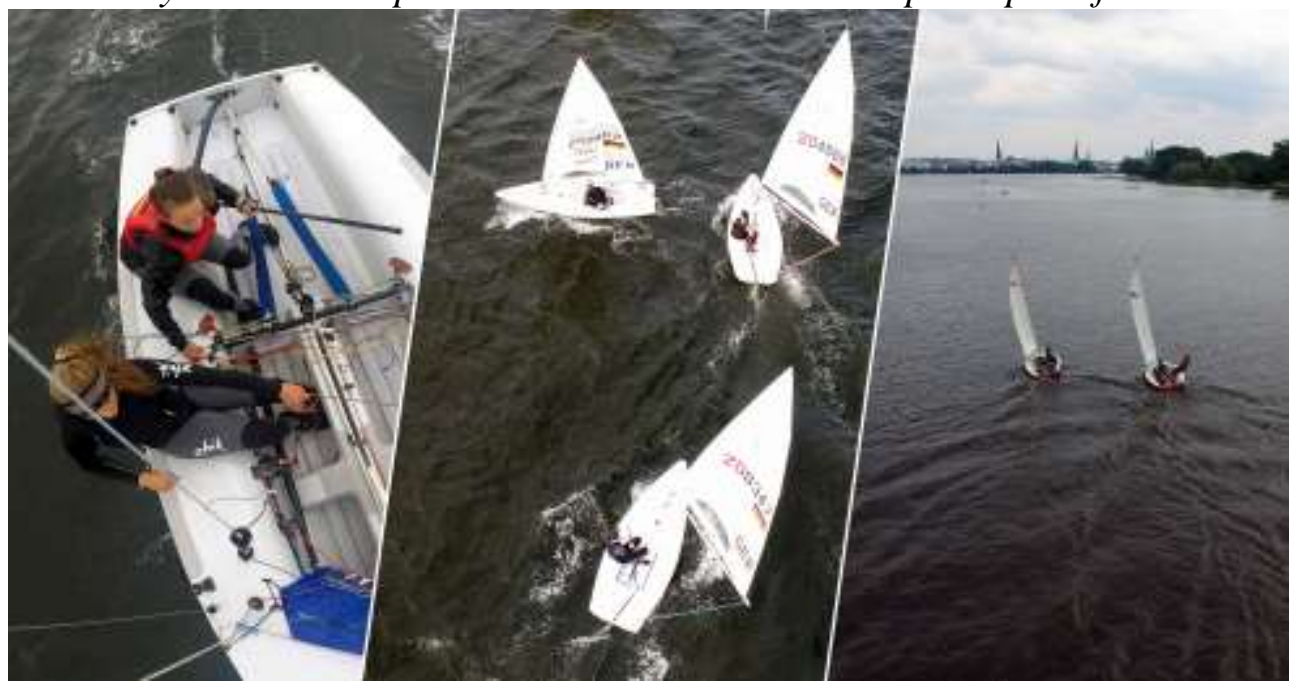

Source: Hebbel-Seeger. 


\section{Video Drones in Competence-Oriented University Teaching}

"In the scientific-academic context, competence must be defined as the ability to act appropriately, responsibly and successfully in areas that are characterized by high complexity, novelty and high demands on solution quality. The ability to act in this way includes integrated bundles of complex knowledge, skills, abilities, motivational orientations and values in relation to the requirements areas." (Schaper 2014)

Expertise in the fields of study of media management and (sports) journalism are primarily oriented towards events and their media communication. While media managers communicate the event experience and make it tangible for spectators, those present or even participants (sportsmen and sportswomen), sports journalists focus on a discursive, communicative discussion of events that is made understandable for third parties through reporting, argumentation or criticism. Both courses of study are based on media communication. Through these forms of communication, the experimental space event is mediatized (Reinmann 2016, 236).

Video drones can set special accents in many ways in these forms of mediatization and intensify the experience for recipients. In the university environment they are therefore an almost ideal tool for project-oriented studies and the development of competencies. At the same time, it is still very unusual to come across video drones in university training. In Germany, various programs can be found, above all with regard to cinema films or technical requirements, while application- and competence-oriented programs are rarely to be discovered. An analysis of 16 current programs relating to video drones from universities in the USA also shows that most of the offerings are focused on aeronautical skills or specifics, observation or military and civilian surveillance. Only two programs in Missouri and the laboratory for "Drone Journalism" in Nebraska-Lincoln directly deal with media (journalism) expertise in working with video drones.

This denial of possible expertise-oriented teaching with video drones is surprising in the field of media event communication. Video drones offer several application possibilities in various situational contexts, which are suitable for the university education of media managers and journalists, especially in the mediatization of sporting events:

- Shooting in dangerous environments, such as conflicts, disasters or natural phenomena

- Recordings outside standard sports facilities with comparatively large dances and/or distances to the spectator area, e.g. in water or mountain sports.

- Recordings that require an overview (e.g. from a great height) for a domain-specific understanding in order to capture tactical aspects, for example

- Footage that enables the staging of (sporting) events in dialogue with the surrounding space 
These are just a few examples in which video drones have proven themselves in all forms of medial communication of events in the past. In university project studies, these forms can be taught to media managers and sports journalists in a competence-oriented manner. Practice-oriented work in groups is initially the prerequisite for learning different techniques (application competence), but at the same time the diverse possibilities of media implementation (meditation competence) are also learned. Building on this, the basis for a practice-based research performance (research competence) can be developed in the groups.

With the goal of these three areas of expertise in practice-oriented teaching, we have started an experimental project at the Macromedia University with the support of the State Media Institute Hamburg/Schleswig-Holstein on the use of video drones in university teaching. After a prelude with experiments on the mobile use of video drones, a lab was initiated in which practical and researchoriented group work with video drones, 360-degree cameras and VR environments are possible.

The importance of video drones in sports communication is undisputed, states Gynnild:

"The innovation of drones for journalistic purposes will most likely replace, or, more precisely, supplement visual news coverage on the ground with new kinds of aerial views as well as options for aerial close-ups that were formerly unseen" (Gynnild 2014: 341).

The use of drones in the field of media management is of great importance at major sporting events, especially due to the spatial effect of the generated images. Goldberg, Corcoran and Picard emphasize in the Reuters Report the advantages of video drones for general journalism, "if the scale of events is too large to perceive from their ground locations" (Goldberg et al. 2013: 21). Consequently, they conclude with a view to sports journalism:

"In addition to breaking news and investigative uses, RPAS can be used in sports coverage of bicycle races, marathons, and football matches where they can provide different visual perspectives than the cable- and track - based robotic cameras" (Ibid).

Furthermore, the Reuters Report points out possible reciprocal effects of video drones in journalistic communication: "Because application of drones in journalism is only just emerging, it is unknown how the public will react to their use." (Ibid 24).

Other possible applications in sports communication are conceivable. This statement has been tested in various case studies at Macromedia University in group-oriented learning processes. Media Management and Sports Journalism students developed initial results in various project studies, which can be summarized as follows: 
- An aestheticization of the communication space is to be noted. The use of video drones in sports communication changes the perspectives of space. Particularly during sporting movements, images with a new aesthetic are made possible, which generate a changed effect on reception. This has been tested e.g. with a bird's eye view from a swiss TV channel (Schweizer Fernsehen - SRF) on the Lauberhorn downhill ski run and is now a standard feature at many sporting events. Based on theoretical knowledge, a practice-relevant implementation should be followed in the project study. Various groups filmed an inner-city cycling race and a triathlon using video drones to create aesthetically sophisticated images. This is not only of great interest in the field of event management but is also journalistically relevant. Furthermore, a study project at an event in Timbersports has shown the great attraction of video drone images also in use for sports PR. For example, the use of video drones in the area of local city marketing was successfully tested in a project in cooperation with the then Hamburg Committee for the 2024 Olympic Games.

- The use of video drones can lead to an expansion of communication possibilities. With little effort, the variety of camera perspectives is significantly increased. The project-oriented requirement for the group members was to gather practical experience in order to work through these in theory afterwards. In these projects, several perspectives have been tried out in practice, in particular when the drone accompanies the sporting movement (like a rope or train camera) unusual images are made possible. In training with a top-class football club it became clear how video drones can also achieve advantages in sports science applications. The new perspectives broaden sport communication, especially in terms of changing temporal perspective (dynamics vs. slowdown), but also in terms of visual clarity (training control).

- Particularly in sports, a change in the communication area can be observed. The use of video drones in sports communication enables new camera perspectives, which were previously not available (e.g. water sports) but can also be limited (indoor sports) due to the changeable position. Two different study projects proved this contradictoriness in practice: On the one hand, in cooperation with the German parakanu silver medal winner Edina Müller, it was shown how very large-area sports can benefit from video drones. This makes the sports space visible to spectators without great effort, e.g. from helicopters, so that the performance can be experienced. Other water sports (sailing) or golf and horse riding would also be conceivable here. On the other hand, in cooperation with a social boxing project, the limits became apparent. The communication area in a hall is not suitable for the use of video drones. The high social impact of working with video drones became clear in these group projects, as the cooperation with the athletes in these sports was very demanding.

- An interesting advantage of the use of video drones can be discovered in the field of media neglected sports by the change in the organization of 
communication. Video drones offer an opportunity for marginal sports without extensive organizational resources to generate professional images at events. With a drone, for example, visual communication in the management area or up-to-date, journalistic game reporting in sports is possible from a sensible, elevated camera position even without the complex and expensive installation of grandstands or camera stands. This was confirmed by a study project with a team in Australian football: The German marginal sport could be filmed by a video drone with communicatively appealing pictures despite the lack of grandstands or camera frames.

In addition to these exemplarily presented results, two interesting consequences for the use of video drones in sports communication arose. Especially when the drone was used in a hall (boxing), the athletes were distracted by the device and its noises. These reciprocal effects strongly influenced the sporting action. Furthermore, it became clear that the drone's camera work repeatedly followed certain patterns in order to depict the sporting action. In various group works it was therefore suggested to develop different drone camera movements for different sports, similar to the already existing camera work of traditional sports communication.

In summary, the projects have demonstrated the advantages of the use of video drones in sports communication on several levels during their studies. Not only in the visualization of sports events, but also for the sports journalistic communication of these events through current media. Video drones are cheaper and easier to use and implement than comparable helicopter-supported cameras. The use of drones will not replace traditional event communication but will certainly complement it.

The experience gained in the student projects at the individual and organizational level will in future require a research-based discussion in order to systematize the results. The group work in this exciting and interesting technical field has increased the motivation of the students in the academic field.

\section{Summary and Outlook}

Drones are no longer just hype. It is not a question of "playing" with the technical possibilities, but of dealing with a significant content of our current media reality from an academic perspective.

The overall objective of a university degree in media management and (sports) journalism is concretized in the understanding, explanation, application and further development of usage options and communication solutions. The acquisition of knowledge about domain-specific peculiarities, alternatives and combinatorial possibilities of the use of video drones, knowledge about and practical observance of legal requirements, the assessment and handling of situational conditions (especially space and weather) as well as the acquisition of a 
basic technological and technical understanding form the basis for a hermeneutic understanding and practical use.

"With the concept of situational learning, application-oriented knowledge content is at the center of interest, professional contexts are integrated into the learning situation, experiences are gained, as well as teamwork and the division of knowledge in social groups are promoted." (Reinmann 2009: 41)

These are not only ingredients for research orientation in teaching but also prerequisites for development of expertise that enable students to anticipate and influence future developments in media communication in sport. In perspective of an intensive research achievement, the focus could lie on a kind of textbook for the exemplary use of video drones in sports communication and the academic benefit.

\section{References}

Arnold P, Prey G, Wortmann D (2015) Digitalisierung von Hochschulbildung: E-Learning Startegie(n) noch up to date?[ Digitizing Higher Education: E-Learning Startegy (s) Still Up to Date?] In Seufert S, Ebner M, Kopp M, Schlass B (Hrsg.). E-Learning Strategien für die Hochschullehre, 51-70. Norderstedt: BoD.

Chamberlain P (2017) Drones and Journalism. How the Media is Making Use of Unmannend Aerial Vehicles. New York: Routledge.

De Graaff E, Kolmos A (2006) History of problem-based learning and project- based learning. In Graaff ED, Kolmas A (Hrsg.). Management of change, 1-8. Boston: Sense Publishers.

Design-Based Research Collective (2003) Design-based research: An emerging paradigm for educational inquiry. Educational Researcher 32 (1): 5-8.

Fung D (2017) A connected curriculum for higher education. London: UCL Press.

Goldberg D, Corcoran M, Picard RG (2013) Remotely Piloted Aircraft Systems \& Journalism Opportunities and Challenges of Drones in News Gathering. Report. Reuters Institute for the Study of Journalism, Oxford University, Oxford. Retrieved from https://bit.ly/2R66b4G. [Accessed 29 June 2018].

Gynnild A (2014) The Robot Eye Witness. Extending visual journalism through drone surveillance. Digital Journalism 2(3): 334-344.

Handke J (2017) Handbuch Hochschullehre Digital. Handbuch für eine moderne und mediengerechte Lehre ( $2^{\text {nd }}$ revised edition). Baden-Baden: Tectum.

Hebbel-Seeger A (2016) Video drohnen in der Event kommunikation[Video drones in event communication]. In Hebbel-Seeger A, Horky T, Schulke HJ (Hrsg.). Sport als Bühne. Mediatisierung von Sport und Sport großveranstaltungen, 326-345. Aachen: Meyer\&Meyer.

Hebbel-Seeger A, Horky T, Theobalt C (2017) Usage of Drones in Sports Communication - New Aesthetics and Enlargement of Space. Athens Journal of Sports 4 (2): 89-105. Retrieved from https://bit.ly/2R3hQB2.

Hebbel-Seeger A, Vohle F (2016) Innovative Videoformate im Sport zwischen Training and Marketing [Innovative video formats in sports between training and marketing]. Retrieved from https://adobe.ly/2NWoS8M. 
Huber L (2009) Warum Forschendes Lernen nötig und möglich ist[Why research learning is necessary and possible]. In Huber L, Hellmer J, Schneider F (Hrsg.). Forschendes Lernen im Studium. Aktuelle Konzepte und Erfahrungen, 9-35. Bielefeld: Webler.

Kolb DA (1984) Experiential Learning. Englewood Cliffs, NJ: Prentice Hall.

McKenney S, Reeves T (2012) Conducting educational design research. London: Routledge.

Mieg HA, Lehmann J (2017) Forschendes Lernen: Wie die Lehre in Universität und Fachhochschule erneuert werden kann[Research Learning: How Teaching in Universities and Colleges Can Be Renewed]. Frankfurt am Main: Campus.

Nieke W, von Freytag-Loringhoven K (2016) Wissenschaftsdidaktik vor neuen Aufgaben: Bildung durch Wissenschaft[Science didactics facing new challenges: education through science]. Wiesbaden: Springer.

Perrit HH, Sprague EU (2017) Domesticating Drones. The Technology, Law and Economics of Unmanned Aircraft. New York: Routledge.

Reinmann G (2009) Wie praktisch ist die Universität? Vom situierten zum Forschenden Lernen mit digitalen Medien[How convenient is the university? From situated to research learning with digital media]. In Huber L, Hellmer J, Schneider F (Hrsg.) Forschendes Lernen im Studium, 36-51. Bielefeld: Webler.

Reinmann G (2011) Forschendes Lernen und wissenschaftliches Prüfen: die potentielle und faktische Rolle der digitalen Medien[Research-based learning and scientific testing: the potential and factual role of digital media]. In Meyer T, Han-Tan W, Schwalbe C, Appelt R (Hrsg.). Medien \& Bildung. Institutionelle Kontexte und kultureller Wandel, 291-306. Wiesbaden: VS.

Reinmann G (2016) Gestaltung akademischer Lehre: semantische Klärungen und theoretische Impulse zwischen Problem- und Forschungsorientierung[Design of academic teaching: semantic clarifications and theoretical impulses between problem and research orientation]. ZFHE, Zeitschrift für Hochschulentwicklung 11(5): 225244.

Schaper N (2012) Fachgutachten zur Kompetenzorientierung in Studium und Lehre [Expert report on competence orientation in study and teaching]. Bonn: HRK. Retrieved from https://bit.ly/2p0OqIQ. [Accessed 18 June 2018].

Schaper N (2014) Kompetenzorientierung in der Lehre [Competence orientation in teaching]. duz - Deutsche Universitätszeitung 3. Retrieved from https://bit.ly/2OH YDZ6 [Accessed 18 June 2018].

Scheidewind U, Singer-Brodowski M (2015) Vom experimentellen Lernen zum transformativen Experimentieren. Reallabore als Katalysator für eine lernende Gesellschaft auf dem Weg zu einer Nachhaltigen Entwicklung[From experimental learning to transformative experimentation. Real laboratories as a catalyst for a learning society on the way to sustainable development]. Zeitschrift für Wirtschaftsund Unternehmensethik 16(1): 10-23.

Schneider R (2016) Vom entdeckenden zum forschenden Lernen. In Schude S, Bosse D, Klusmeyer J (Hrsg.). Studienwerkstätten in der Lehrerbildung, 107-118. Heidelberg: Springer.

Stock D (2015) Fast and Furious. New Scientist 228: 60-61.

Van Someren MW, Barnard YF, Sandber JAC (1994) The think aloud method: a practical approach to modelling cognitive Processes. London: Academic Press.

Vohle F (2016) Social Video Learning. Eine didaktische Zäsur. In Scheer AW, Wahter C (Hrsg.). Digitale Bildungslandschaften, 175-185. Saarbrücken: IMC. 